también afectará a las regiones sistemáticamente demandantes de fondos o a las listas grises de proveedores con excesivos contratos que ya se va generalizando entre las Direcciones Generales Comunitarias para mejorar la igualdad de oportunidades y la libre competencia. El Mercado Único también va a serlo cada vez más para fondos y ayudas; y como en otros mercados, lo que contará para tener éxito será la orientación estratégica, la previsión táctica, la preparación negociadora y la habilidad operacional de cada participante.

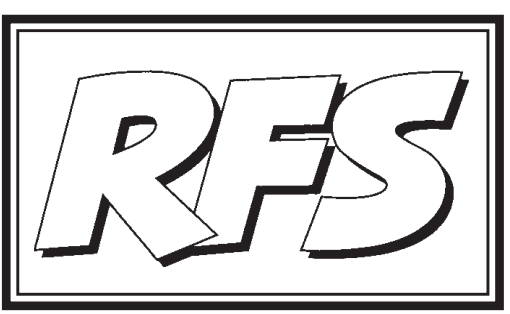

NOTA DE LA REDACCIÓN

Como nuestros lectores habrán observado, la estructurevista. Presentamos a continuación una crónica de as Jornadas de ACADE en ETEA y una selección de tres ponencias presentadas en las mismas.

La ayuda del Ayuntamiento de Córdoba ha permitido aumentar la tirada de este ejemplar con el fin de distribuirlo entre los asistentes y personas interesados

Revista de Fomento Social, 59 (2004), 351-357 por la temática de estas Jornadas.

\title{
Formación de Recursos Humanos y Cooperación al Desarrollo. II Jornadas de ACADE en ETEA
}

$M^{\underline{a}}$ LUz ORTEGA CARPIO ${ }^{1}$ y José J. ROMERO RODRÍGUEZ

Más de 200 profesionales del mundo de la cooperación se dieron cita en ETEA (Córdoba) el día 14 de mayo de 2004 para asistir a las Jornadas Formación en Recursos Humanos y Cooperación al Desarrollo organizada por la Fundación La Caixa y ACADE (Asociación de profesionales por la calidad de la Cooperación para el desarrollo) con la colaboración del Ayuntamiento de Córdoba ${ }^{3}$. Dado su posible interés para los lectores de la Revista de Fomento

Social, presentamos una breve crónica de este evento.

1 Profesora de ETEA y vicepresidenta de ACADE.

2 Profesor de ETEA.

3 Alguno de los documentos que presentamos a continuación de esta crónica constituyeron aportaciones a las Jornadas, en concreto los artículos de José Antonio Alonso, Carmelo Angulo y Christian Freres. 


\section{a) Qué es ACADE}

La "Asociación de Profesionales por la calidad de la Cooperación para el desarrollo" es, como su propio nombre indica, una asociación de profesionales vinculados a la cooperación, a quienes une la preocupación por conseguir una política de ayuda al desarrollo más vigorosa y eficaz ${ }^{4}$.

ACADE nació con el propósito de contribuir al compromiso que la sociedad española tiene con las tareas de solidaridad internacional. A través de la promoción del análisis y del debate, desde la pluralidad de las respectivas trayectorias profesionales de sus socios, procedentes de la administración pública, la consultoría, la universidad y la cooperación no gubernamental, ACADE pretende promover el enriquecimiento del sistema de cooperación para el desarrollo y favorecer el establecimiento de un marco de relaciones internacionales más justas y provechosas para todos.

En particular, pretende encauzar las propuestas e inquietudes de este colectivo de profesionales, por entender que es imprescindible su participación en la mejora de la calidad de la cooperación para el desarrollo.

\section{b) El planteamiento de las Jornadas de mayo 2004}

Desde ACADE se planteó una jornada que reflexionase sobre la cualificación de los profesionales en la cooperación internacional para el desarrollo. Se parte de la convicción de que la cualificación favorece unas intervenciones con un mayor fundamento técnico, pero también de que la cualificación pasa por hacer de las organizaciones de procedencia organizaciones abiertas al aprendizaje, que entiendan el desarrollo como un proceso abierto y complejo.

La ley de cooperación internacional distingue tres tipos de agentes de la cooperación al desarrollo: personal al servicio de la Administración Pública, cooperantes y voluntarios. A estos agentes han de sumarse aquellos profesionales que trabajando desde dentro de las empresas desarrollan actividades en el ámbito del desarrollo. El número de personas que forman parte de estos colectivos ha crecido en los últimos años, pero semejante

4 Los lectores interesados pueden ampliar esta información en la página Web de la Asociación: www.acadecooperacion.org. Véase, entre otras cosas, el "Informe sobre el estado de la cooperación en España” elaborado por ACADE, a partir de una encuesta a más de 200 profesionales españoles. proceso no ha ido acompañado del desarrollo de un marco normativo que ampare su actuación en el ámbito de la cooperación internacional, ni de la determinación de los conocimientos profesionales requeridos para actuar en los contextos sociales del mundo en desarrollo.

Ante la carencia de un proceso reglado de formación, la cualificación de los profesionales de la cooperación internacional se ha producido bien a través de la experiencia, bien por medio de los cursos de especialización, postgrados y maestrías existentes. No obstante, el panorama de estas titulaciones es heterogéneo en sus niveles de exigencia y en sus contenidos curriculares. Al tiempo, se observa que no siempre las organizaciones e instituciones prestan la debida atención a los aspectos referidos a la formación y cualificación profesional en materia de ayuda al desarrollo de sus colaboradores, personal técnico y cuadros directivos, lo que termina por repercutir sobre la calidad de las intervenciones.

Para profundizar en los contenidos y líneas de actuación posible en este ámbito se ha celebrado unas jornadas en torno al tema: "Formación de Recursos Humanos y Cooperación al Desarrollo". Las Jornadas pretendían explorar los diversos aspectos implicados en la formación de recursos humanos para la cooperación internacional. Fruto de la colaboración entre la Asociación de Profesionales por la Calidad de la Cooperación para el Desarrollo (ACADE) y la Fundación "La Caixa», estas Jornadas tenían sus antecedentes en otras previas, celebradas en mayo de 2003 en Madrid, sobre La calidad en la cooperación internacional al desarrollo. Adicionalmente, las presentes Jornadas contaron con el apoyo del Ayuntamiento de Córdoba.

\section{c) Objetivos de las Jornadas de mayo 2004}

El Objetivo general de estas Jornadas era: "contribuir, mediante el debate y la reflexión colectiva, al estudio de las tareas que pudieran conducir a una mejora de los recursos humanos disponibles para la cooperación para el desarrollo, al objeto de incrementar la eficacia y la calidad de sus intervenciones".

Por su parte, los Objetivos específicos fueron:

- Analizar los contenidos formativos a los que deberían acceder las personas que trabajan en el ámbito de la cooperación al desarrollo.

- Reflexionar sobre las políticas de capacitación y promoción de los 
recursos humanos en las organizaciones e instituciones que trabajan en el ámbito de la cooperación al desarrollo.

- Estudiar los estilos de trabajo de las organizaciones de la ayuda y su efecto sobre la puesta en valor de sus recursos humanos.

- Debatir sobre el marco legal de los recursos humanos en la cooperación al desarrollo.

Las jornadas se celebraron los días 14 y 15 de mayo de 2004 en ETEA - Institución Universitaria de la Compañía de Jesús, Facultad de CC. Económicas y Empresariales adscrita a la Universidad de Córdoba.

\section{d) Desarrollo de las Jornadas del viernes 14 de mayo}

Las sesiones comenzaron con el acto de inauguración que tuvo lugar el viernes 14 por la mañana, con presencia institucional del Ayuntamiento de Córdoba, la Caixa, ACADE y ETEA.

A continuación dos intervenciones - una "del Norte" y otra "del Sur"-permitieron reflexionar sobre el tema genérico: "Talento y talante en el sector de cooperación". Se trataba de reflexionar sobre las actitudes que deben predominar en las actuaciones de cooperación para el desarrollo. Susana Sacavino (Novamerica-Brasil) expuso la visión del Sur; partiendo de la necesidad de "reinventar" tanto la utopía como la ciudadanía, enumeró algunos elementos pedagógicos para la formación de recursos humanos: prácticas que des-velen / re-velen la realidad; que articulen sentidos y significados y saberes; prácticas que nos des-centren; y que generen militancia. Por su parte Luis Arancibia (Entreculturas-España) fue el encargado de exponer la visión del Norte. Comenzó describiendo algunos elementos definitorios del colectivo de cooperantes en el Norte; a continuación describió algunos rasgos de la cooperación internacional que condicionan el modo de actuar (la universalidad, lo virtual, la institucionalidad, lo estructural, la convocatoria general). Luego expuso lo que considera "los mínimos" a compartir entre todos los que se dedican a estas tareas: conocimiento de la realidad, competencia técnica, capacidad para el trabajo en equipo, motivaciones hondas más allá de la ingenuidad inicial y mirada de largo plazo. Concluyó enumerando algunos medios necesarios para ello: formación, legislación instituciones. Las dos ponencias fueron seguidas de debate, y la sesión fue moderada por $\mathrm{M}^{\mathrm{a}}$ Luz Ortega, vicepresidente de ACADE.
Se abordó a continuación el tema central de las Jornadas: La formación en la Cooperación al desarrollo. Esta parte de las Jornadas, moderada por Anna Ayuso (CIDOB - Barcelona) contó con la ponencia "Un análisis de la formación en cooperación y desarrollo en España”, a cargo de Christian Freres (consultor de AIETI - Madrid). El autor ha estudiado en detalle la oferta de los programas formativos (tipo Master) orientados hacia la cooperación y el desarrollo en España. Su trabajo -que se incluye en este mismo número de la RFS-consiste en un análisis del perfil de las diferentes propuestas formativas y una valoración de las mismas. Su ponencia fue comentada por otras tres personas que aportaron, mediante sendas comunicaciones más breves, el punto de vista de tres colectivos potenciales demandantes de formación para la cooperación: Carlos Mataix (Vicepresidente de la CONGDE - Madrid) "La necesidad formativa de las ONGD"; Begoña Arrizabalaga (CMA Consultores Asociados) "La necesidad formativa de las agencias de consultoría”; y Antonio Carlos Zurita (Gerente del Fondo Andaluz de Municipios para Solidaridad Internacional - FAMSI) "La necesidad formativa de la administración local".

Por la tarde, Manuel Iglesias Caruncho (Director del Área de Cooperación de la Escuela Andaluza de Salud Pública - Granada ) expuso el tema "Derechos y deberes del profesional de la cooperación". Su propuesta partió de la constatación de la ausencia en España, a estas alturas del año 2004, de un estatuto del Cooperante. Planteó a continuación los principales asuntos de interés relacionados con los derechos y deberes del personal de cooperación: qué personas deban incluirse en una Ley Reguladora de dicho Estatuto cómo deba funcionar el pago de impuestos a la Hacienda Pública y de cuotas a la Seguridad Social; qué problemas plantea el retorno de los cooperantes españoles expatriados; y otras varias cuestiones de menos entidad, pero de interés. Su ponencia fue comentada, en sendas breves intervenciones, por tres profesionales de diferentes ámbitos de la cooperación: Fernando Mudarra (Director OTC - AECI Bolivia) habló sobre "El profesional de la cooperación en el terreno"; Félix Fuentenebro (Secretario General de Médicus Mund -Barcelona) habló de "El estatuto del cooperante, la visión de la CONGDE"; y, por último, Teresa González (Madre Coraje, Jerez) intervino sobre el tema "El profesional de la cooperación en Andalucía".

La clausura de las Jornadas propiamente dicha consistió en dos intervenciones. Habló primero Carmelo Angulo (PNUD-Argentina) quien expuso el tema: "Nuevos retos de la formación para el desarrollo".

El cierre estuvo a cargo de José Antonio Alonso (Presidente de ACADE) 
que tituló su intervención: "El desarrollo como proceso abierto al aprendizaje: diez desafíos para la ayuda”.

El texto de estas dos intervenciones aparece a continuación.

La jornada del viernes concluyó con una Recepción del Ayuntamiento de Córdoba en los Jardines del Alcázar de los Reyes Cristianos.

\section{e) Taller del sábado 15 de mayo}

El encuentro de la mañana del sábado tenía un formato diferente. No era, como la víspera, una jornada abierta, sino un taller de reflexión o sesión de trabajo participativo en tres grupos de 10-12 personas con el fin de hacer propuestas concretas -a desarrollar por ACADE en colaboración con las entidades que parezcan oportunas- sobre el tema central de las Jornadas: Recursos humanos y formación. El taller contó con la presencia de un nutrido y cualificado número de profesionales del ámbito de la cooperación. Desde el sector no gubernamental, por ejemplo, asistieron todos los presidentes que la Coordinadora nacional de ONGD ha tenido desde su nacimiento hasta el momento; así como la junta directiva de la Coordinadora andaluza de ONGD y responsables de numerosas ONGD. Desde el ámbito de la administración se contó con la presencia de representantes tanto nacionales como de distintas Comunidades Autónomas (Galicia, Andalucía, Cataluña y País Vasco). También se contó con la presencia de consultores y expertos universitarios, directores de Master en cooperación (CICODE-Granada, DEUSTO-Bilbao, ESADE-Barcelona, ETEA-Córdoba, ICEI-Madrid, IUDC-Madrid, Centro de Cooperación para el Desarrollo de la Universidad Politécnica de Valencia), etc.

Jaime Atienza (CARITAS-Madrid), Ana Arancibia (INTERED-Madrid) y Marta Arias (INTERMON-OXFAM Madrid), todos ellos miembros de ACADE se encargaron de dinamizar el taller en su conjunto y cada uno de los grupos. El planteamiento o esquema de trabajo sugerido por los coordinadores de esta segunda jornada para esta sesión de seminario consistió en agrupar las ideas y sugerencias, de cara a la formación para la cooperación, recogidas en las intervenciones de la jornada del viernes 14 de mayo en cuatro grandes bloques, que se reproducen telegráficamente a continuación:

1. Habilidades y competencias.

2. Valores (identidad del colectivo): compromiso, mirada de largo plazo, visión clara de la dimensión estructural del desarrollo, preocupación por cambiar al Norte etc.

3. Capacitación técnica: instrumentos y ámbitos temáticos.

4. Relaciones norte-sur como mecanismo/proceso promotor de aprendizaje: relaciones institucionales y personales; proceso mutuo de aprendizaje; humildad y flexibilidad ante "el otro".

A partir de ahí se solicitó a los miembros de los grupos seguir la siguiente pauta de trabajo:

a) debate previo sobre si estos elementos son los necesarios o suficientes, o si era preciso introducir, eliminar, modificar alguno de ellos;

b) análisis de los epígrafes contenidos en estos requerimientos formativos desde el punto de vista de las variadas instituciones de las que provenimos;

c) propuesta de líneas de acción concretas para el futuro.

Los grupos hicieron reflexiones y sugerencias, que luego fueron recogidas en una puesta en común y que constituirán un material de base para el trabajo ulterior de ACADE sobre las siguientes líneas de trabajo: la adaptación de la oferta formativa de las universidades; las organizaciones y la formación de recursos humanos: estilos de dirección, valores y rutinas organizativas; las relaciones Norte-Sur como mecanismo promotor del aprendizaje.

En resumen, unas densas jornadas de reflexión que, sin duda, permitieron a los participantes profundizar en los retos que se plantea la formación para la Cooperación. Corresponde ahora a ACADE recoger los frutos de esta reflexión y proponer iniciativas y medidas operativas para ayudar a la mejora de este importante componente de todo el sistema de ayuda al desarrollo. 